\title{
Regulating genetic engineering guided by human dignity, not genetic essentialism
}

\author{
Benjamin Gregg (1), University of Texas at Austin; Lund University
}

AвSTRACT. How might a liberal democratic community best regulate human genetic engineering? Relevant debates widely deploy the usually undefined term "human dignity." Its indeterminacy in meaning and use renders it useless as a guiding principle. In this article, I reject the human genome as somehow invested with a moral status, a position I call "genetic essentialism." I explain why a critique of genetic essentialism is not a strawman and argue against defining human rights in terms of genetic essentialism. As an alternative, I propose dignity as the decisional autonomy of future persons, held in trust by the current generation. I show why a future person could be expected to have an interest in decisional autonomy and how popular deliberation, combined with expert medical and bioethical opinion, could generate principled agreement on how the decisional autonomy of future persons might be configured at the point of genetic engineering.

Key words: human genetic engineering, regulation, dignity, moral status of the human genome, decisional autonomy, future persons, social construction

$\mathrm{W}$ e humans have bodies in a biological sense. By contrast, we are our bodies in the cultural sense of how, in a normative sense, we collectively regard our own bodies and the bodies of others. The biological is given; the cultural, socially constructed. With the rapidly increasing capacity to manipulate future bodies genetically, toward influencing some traits of future bodies, the distinction between nature and culture weakens but hardly vanishes. To be sure, the sphere of human nature has always shared a porous boundary with human culture. Consider several examples of how humans construct culture. Disease, pathology, and medicine have more to do with nature than culture but are not culture-free. Another example: "human nature" with respect to what is "normal," what is "illness," what is "harm," and what constitutes a physical disease or cognitive illness involves both natural and cultural elements. A third example: notions of human freedom, equality, and rights have mostly to do with culture-but they are not nature-free.

My concern is with genetically based congenital diseases. Here, too, nature and culture are porous vis-à-vis one another. Medical practice works with a naturalistic

doi: $10.1017 /$ pls.2021.29

Correspondence: Benjamin Gregg, University of Texas at Austin, Texas, USA; Lund University, Lund, Sweden. Email: bgregg@austin. utexas.edu conception of disease, defined as a pathology whereby a particular bodily system departs from "natural functioning," with adverse consequences for the individual. Even this naturalistic conception has a cultural element: the evaluation of a particular, natural, biological process as harmful.

Disease so understood is neither wholly empirical nor wholly normative (whereby I understand all social and moral norms to be social constructs). To the extent that abnormal functioning can be identified by science, it is something objective. To the extent that humans frame the abnormal as adverse-resulting, for example, in the individual's diminished well-being - the term disease has a normative, hence intersubjective, component, even as the phenomenon itself is objective. In other words, a biological abnormality may have consequences for the individual's life that human communities define in valueladen ways (e.g., as something "bad" for the person). At an extreme, if humans understand a particular biological process to be harmful to its carrier, the process may then be understood to be dysfunctional (much in the way that human communities classify some flora as "weeds" and some animals as "vermin").

What humans regard as the negative quality of biological processes, and call "disease," is in fact a quality identified by human values, not natural scientific observation. Here, human interests (value judgments) frame natural phenomena in cultural ways. The framing of a 


\section{Genetic engineering guided by human dignity}

particular corporal condition as diseased is the normative framing of an empirical phenomenon. For example, aging is a normal feature of organic life. That most elderly persons, but not most young persons, are frail, is hardly a disease. By contrast, Hutchinson-Gilford progeria syndrome is a disease: an incurable, randomly occurring genetic mutation that leads to a bizarrely rapid rate of senescence (such as slow growth and hair loss), beginning in the first year or two of a child's life and usually leading to death by age 17 .

Thus, the claim that an abnormal functioning is not in the individual's best interest, that it degrades their potential well-being, that a particular bodily process is harming them in a particular way, is normative, not natural. Such a claim does not require a notion of "human nature" but is in fact often accompanied by some such notion. Any notion of human nature can only be a culturally particular conception, such as the "genetic essentialism" that I analyze in later pages as a particular notion of human dignity.

I examine nature/culture porosity with respect to human genetics. The technical capacity to manipulate the human genome renders all the more porous the dichotomous quality of being human, that is, being an evolved organism with a capacity to socially construct aspects of its environment as well as itself. The back-and-forth flow between human biology and cultural norms increases as the physical object of genetic alterations intersects with cultural constructions of the normative acceptability of such alterations. At that intersection, a question poses itself: how might human genetic engineering best be regulated? The question is vexed. On the one hand, some forms of genetic manipulation may eliminate, in human embryos or fetuses, some genes that cause some diseases. On the other, the idea of rendering species biology fungible to human design is an abiding source of unease.

Consider CRISPR-Cas9, one of the most powerful genome-editing technologies, possibly even a "magic bullet for generating customized gene and cell therapies, more targeted treatments" and maybe even for "direct editing out of disease-causing genes in human embryos" (Jasanoff et al., 2015, p. 28). It modifies an organism's genetic code by editing the order of DNA sequences, "adding, deleting, or altering genetic material at a particular location in its genome" (Charo, 2018, p. 344).

Political communities in coming years will face the challenges of responding to questions raised by CRISPR and other forms of genetic manipulation. They will confront difficult moral, legal, and political questions:
Could genetic manipulation emancipate humanity from genetic disease-or might genetically modified persons be robbed of individual autonomy and personal freedom by the modifiers and thus rendered captives of others' preferences? What rights might be legislated to allow or disallow various forms of genetic editing? Should parents have a legal right to determine what, in their opinion, would be the "best" genetic inheritance for the lives of their future children? Or does a person not yet born-a future person-have a legal right to be free of irreversible genetic enhancement desired by their parents?

Normative questions demand normative answers; natural science cannot answer them. The widely deployed but often undefined term "human dignity" offers itself as one kind of normative answer. As I will show, it offers-at least from a consequentialist standpoint-a peculiarly political route to thinking critically about possible legal regulations of human genetic engineering: as the individual's decisional autonomy. But the term offers as much only if it can be defined in a way that is culturally plausible and does not contradict a naturalistic understanding of our species (one that does not contradict modern medical practice). Such a definition would capture the porosity of human culture and human nature. It would find expression in the human species taking increasing measures of control over its own evolution.

The notion of decisional autonomy might seem implausible in the context of human embryos at the point of genetic engineering, when there is no person who could exercise autonomy through participation in deliberation about the problems and prospects of genetic manipulation. Here, there is no person who could veto the planned manipulation of the embryo from which the future person will develop. Only when the future person becomes a current person is decisional autonomy present. But at that point, the person can only react to a fait accompli-to their having been genetically modifiedwith no means to reverse it.

I draw on the idea of a child's right to respect for their best interests to show that the future person's dignity is not violated by the genetic modification of the embryo from which they developed. While the principle of the child's best interest does not engage the autonomy of the child itself, the child's circumstances are analogous in some ways to the future person: one day, both will have interests which current persons, in deciding matters of genetic manipulation, should take into consideration today. They should consider how the planned genetic modification might serve the future person's future 


\section{Benjamin Gregg}

interests. Recognizing those interests today offers a placeholder for future autonomy. Genetic manipulation of the embryo is like preventive medicine in a sense: it can serve the future person's future autonomy.

I propose a way out of this political aporia in six steps. (1) I begin by analyzing the notion of the human genome as invested with a moral status, which leads to genetic essentialism. (2) I show that a critique of genetic essentialism is hardly a strawman and (3) argue against defining human rights in terms of genetic essentialism. (4) I develop an alternative to genetic essentialism: dignity as a future person's decisional autonomy, held in trust by the current generation. (5) I articulate a future person's interest in decisional autonomy and (6) sketch a form of deliberation, within political community, toward principled agreement on how the decisional autonomy of future persons might be configured at the point of genetically engineering the embryo from which that future person will develop.

\section{The human genome invested with an inherent moral status}

Human biology and cultural norms sometimes intersect in the politics of health even as the respective spheres of health and politics pursue distinctly different objectives. (a) Health norms seek a path from illness to health whereas (b) political norms offer ways to evaluate that path in terms of socially constructed norms.

(a) If successful, human germline gene editing may offer heritable "therapeutic treatments of genetic disorders" (Kang et al., 2016). From a standpoint of health, the benefits of genetic "information manipulation" extend far beyond the "prevention of monogenic diseases" and "personalized assisted reproductive technology" (Ishii, 2017, p. 46). Consider several examples:

- Some analysts regard gene editing as a "reliable molecular toolbox" (Bayat et al., 2018, p. 107) to "precisely alter genomes for numerous applications" (Batzir et al., 2017): from basic research to clinical application, and from developing "animal models for genetic disorders" to "gene therapy to combat virus infectious diseases," and even to "correct monogenic disorders in vivo or in pluripotent cells" (Huang et al., 2017, p. 3875).

- Germline genome editing in human embryos can program cells "for diverse applications, including regenerative medicine and cancer immunotherapy" (Ho \& Chen, 2017, p. 57).

- It can prevent parents' giving serious genetic diseases to their offspring (Ishii, 2017, p. 418). It can correct "mutations in patient cells," and unique gene therapies can screen out causative mutations and identify "rare genetic disorders and non-exonic mutationcaused diseases" (Miyamoto et al., 2018, p. 133).

- It can enhance the "efficacy of genome editing in the early embryo" and enable the "generation of allele types previously incompatible with in vivo mutagenesis” (Mianné et al., 2017, p. 68).

- Personalized, molecular surgeries on "genetic DNA directly target the cause of the disease in a personalized and possibly permanent manner"; they "could be combined with traditional surgery, radiation therapy, or chemo/targeted therapy" (Tang \& Schrager, 2016, p. 83).

- By "replacing the mutation-carrying mitochondria of zygotes or oocytes at risk with donated unaffected counterparts," germline genome editing in human embryos may prevent a "broad range of incurable inborn maladies" caused by mutant mitochondrial DNA (Adashi \& Cohen, 2018). While "no curative treatment for patients with mitochondrial disease" exists, germline gene replacement therapy (unlike prenatal and preimplantation diagnosis) may someday prevent transmission of mitochondrial disease (Amato et al., 2014).

- Germline genome editing in human embryos promises a future in which cardiovascular diseases could be "cured by administering a cocktail of CRISPR/Cas9 based therapeutic agents, which functions like a vaccination rather than medications that have to be taken daily" (Li et al., 2016, p. 193).

(b) Now consider a relevant political standpoint: the view that germline manipulation seeks to reduce genetic chance by changing, genetically, unwanted outcomes of the gene pool "lottery" or by precluding such outcomes in the first place, thus "rewrit[ing] the gene pool of future generations" (Cyranoski, 2019, p. 440). By reducing the degree to which humans are chance products of sexual reproduction, germline manipulation increases the degree to which the engineers-but neither the engineered nor their descendants-exercise some choice over some of the genetic traits of future human beings.

An array of prominent international documents (as well as various ethicists and some scientists) adopt a political viewpoint in claiming that genetic modification 


\section{Genetic engineering guided by human dignity}

harms the future person in their dignity. (One notable exception: the Nuffield Council on Bioethics [2018, pp. 93-94] rejects the notion of dignity, in light of its abiding indeterminacy in meaning, as the guiding principle for regulating human genome editing.) For example, the International Bioethics Committee's 2015 "Report of the IBC on Updating Its Reflection on the Human Genome and Human Rights" claims that manipulation would "jeopardize the inherent and therefore equal dignity of all human beings" (para. 107). And the 1997 Convention for the Protection of and Dignity of the Human Being with Regard to the Application of Biology and Medicine (hereafter the Oviedo Convention) - the first legally binding international instrument regulating biomedicine, binding some European nations - states that the abuse of human germline genetic engineering "may endanger not only the individual but also the species itself" (art. 13). Its preamble identifies a "need to respect the human being both as an individual and as a member of the human species" and to recognize the "importance of ensuring the dignity of the human being."

These various instruments practice what I call "genetic essentialism." It is counterintuitive from a naturalistic standpoint: it does not accord with the mundane structure of evolved life such as the "basic categories of our 'intuitive ontology' (i.e., the ontology of our semantic system), such as person, animal, plant, and substance" (Atran \& Henrich, 2010, p. 20). Genetic essentialism is rather a kind of folk biology; it construes our species teleologically. It depicts an evolved life form as an otherworldly essence that entails human dignity. The notion of human dignity often functions in international instruments as a regulative principle for biotechnological manipulation. Even as the notion violates our intuitive ontology, it authenticates what adherents regard as the peculiar moral status of our species. For adherents, the authority of the notion shields it from the kind of logical or empirical scrutiny that a naturalistic standpoint perpetually faces as a matter of its self-understanding as a scholarly enterprise.

The notion of genetic essentialism is the idea that human germline identity constitutes a cultural sharedness on the basis of genetic sharedness. According to the Universal Declaration of Human Rights (1948), species membership as such somehow unifies all individual members in a genetic essentialist identity. The Declaration claims that "in a symbolic sense," the human genome is the "heritage of humanity" (art. 1). It urges protection of the human genome's purported moral status-by not allowing its manipulation-as a matter of preserving human dignity. Similarly, the International Bioethics Committee (2015) asserts that the human genome is "one of the premises of freedom itself" and not simply "raw material to manipulate at leisure (para. 128). Finally, the U.S. President's Council on Bioethics (2002) rejects human genetic engineering by moralizing natural reproduction: "a begotten child comes into the world just as its parents once did, and is therefore their equal in dignity and humanity” (p. 100).

\section{A critique of genetic essentialism is no strawman}

Before pursuing my analysis of dignity in part 3, I pause to establish that a critique of genetic essentialism today is hardly a strawman. Even though (a) genetic essentialism is mistaken, (b) it is still widespread and (c) can be dangerous socially, politically, and institutionally.

(a) Human genetic essentialism is genetically inaccurate in misconstruing genes as a mechanism of causation along several dimensions. First, it involves reductionism and determinism, obscuring nongenetic factors including human culture - of human experience and behavior. Second, it misconstrues patterns of human genetic variation by ignoring multifactorial genetics and population thinking, which studies the very small percentage of the human genome containing all genetic differences between any two persons (a mere $0.1 \%$; see Rosenberg, 2011). While genetic essentialism predicts greater variation between any two human groups than within any single group, population thinking demonstrates greater variation within any particular group than among different groups (see Lewontin, 1972). Third, it does not account for how complex human traits, such as intelligence, are responsive to and conditioned by natural, social, and cultural environments (see Bratsberg \& Rogeberg, 2018). Fourth, it misconstrues genetic heritability as an absolute value when, in fact, biological traits result from the entwined vectors of genes, environment, and contingency. Heritability cannot be generalized as a measurable value for all humans (that is, one cannot say that some percentage of a particular trait is determined genetically and the rest, environmentally). Further, specific populations inherit certain traits under specific circumstances.

(b) Most biologists and philosophers of biology reject an intrinsic form of genetic essentialism, if by "essentialism" 


\section{Benjamin Gregg}

we mean something like "in virtue of what an organism is a member of a certain Linnaean taxon; the issue of what makes an organism a member of that taxon; the issue of the very nature of the taxon" (Devitt, 2008, pp. 347-348). Consider a sampling of opinion: "the vain search for the undiscovered and undiscoverable essence of the term species" (Darwin, 2004, p. 381); "Essentialism about species is today a dead issue" (Sober, 1992, p. 249); "The proponents of contemporary species definitions are all agreed that species have no essence" (Rosenberg, 1985, p. 203); "Folk essentialism is both false and fundamentally inconsistent with the Darwinian view of species" (Griffiths, 2002, p. 72); "no intrinsic genotypic or phenotypic property is essential to being a member of a species" (Sterelny \& Griffiths, 1999, p. 186); "biologists and philosophers of biology typically regard essentialism about species as incompatible with modern Darwinian theory" (Okasha, 2002, p. 191); "it is widely recognized that Darwin's theory of evolution rendered untenable the classical essentialist conception of species" (Dupré, 1999, p. 3).

Yet many scholars are persuaded of a relational form of genetic essentialism: "species ... are associated with no nonrelational real essence" (Matthen, 1998, p. 115); "the essential properties that make a particular organism a platypus ... are historical or relational" (Sterelny \& Griffiths, 1999, p. 186); "On all modern species concepts ... the property in virtue of which a particular organism belongs to one species rather than another is a relational rather than an intrinsic property of the organism" (Okasha, 2002, p. 201); there is "close to a consensus in thinking that species are identified by their histories" (Sterelny \& Griffiths, 1999, p. 8); "Two organisms are conspecific in virtue of their historical connection to each other, not in virtue of their similarity" (Sober, 1993, p. 150); "If species are interpreted as historical entities, then particular organisms belong in a particular species because they are part of that genealogical nexus, not because they possess any essential traits. No species has an essence in this sense" (Hull, 1992, p. 313). One upshot: boundaries between and among different species are fuzzy not sharp. Such biological indeterminacy undermines an essentialism that understands essences as determining category boundaries, where the "very basis of the categories is determined by the essences that underlie them" (Heine et al., 2019, p. S20).

(c) Evidently belief in genetic essentialism is widespread among laypersons (see Heine, 2017). Heine and colleagues (2019) offer one theory: "People's lay understanding of genes shares many features in common with their intuitions about essences. Like essences, an individual's genes are present at birth, and despite the huge physical and psychological transformations that occur across one's lifetime, they remain stable and largely unchanged throughout their lives. An individual's genes are unique to that individual (barring any monozygotic twins), and approximately half of them can be transferred to their offspring" (p. S20). The idea of an essence offers a strong form of identity. Perhaps genetic essentialism provides its adherents a satisfyingly strong form of human identity.

Essentialist beliefs can render genetic attributions a particularly troubling influence on a person's or a group's perceptions of other persons or groups and may lead to various forms of discriminatory behavior. For example, Haslam and Levy (2006) found that the "belief that homosexuality is biologically based, immutable, and fixed early in life," that "it is cross-culturally and historically universal," and "that "it constitutes a discrete, entitative type with defining features," predicts antigay prejudice "independently of right-wing authoritarianism, social dominance orientation, and political conservatism" and demonstrates that "essentialist beliefs mediate associations between prejudice and gender, ethnicity, and religiosity" (p. 471). According to Gil-White (2001), when "ethnic actors represent ethnic groups as essentialized 'natural' groups despite the fact that ethnic essences do not exist," they may be drawing on a "mental module that initially evolved to process species level categories" (p. 515) - because "interaction with outgroup members is costly because of coordination failure due to different norms between ethnic groups, thinking of ethnic groups as species adaptively promotes interactional discriminations towards the in-group (including endogamy)" (Gil-White, 2001, p. 515).

Essentialist beliefs can lead to various forms of harm, from prejudice and discrimination (Andreychik \& Gill, 2015; Ching \& Xu, 2018; Morton et al., 2009) to violence and even genocide (Jackson \& Depew, 2017). It can lead to less overt forms of harm as well. In the form of genetic exceptionalism, it may misguide professionals in genetically informed health care. According to Evans and Burke (2008), contemporary medical systems treat a patient's genetically relevant information as immutable (other than nontrivial somatic mutations) and unique, as a powerful identifier and predictor of risks of disease and responses to medication. For these reasons, some observers discourage the sharing of such information even in clinical settings, for example in the patient's detailed, highly personal medical record. In fact, only 


\section{Genetic engineering guided by human dignity}

in rare, highly penetrant genotypes does genetic risk prediction have a quality distinct from most medical risks; genetics are but one of many disease sources; and is not more personal than other, non-genetic types of information, from blood pressure to cholesterol level. The more genetic information becomes useful in medical diagnosis and decision-making, the greater the access that health providers should have. But essentialist-based genetic exceptionalism in clinical settings makes the patient's genetic information accessible to health providers "in inverse relation to its clinical utility" (Evans \& Burke, 2008, p. 500).

\section{Against defining dignity in terms of genetic essentialism}

Genetic essentialism "incorporates a static vision of a human genome that contains only 'human' genes that are transmitted vertically from generation to generation" (Charo, 2018, p. 348). It rejects the bioengineering of traits that are otherwise unusual in humans. It rejects a genetic engineering that would merely widen the distribution of an already existing trait. Even engineering that brought to expression traits not yet present in the species would compromise the "essential" condition of the human individual and species-although "even traits unfamiliar to us as a species may nonetheless be perfectly consistent with our notion of humans" (Charo, 2018, p. 348).

In this way, genetic essentialism imagines the integrity of the human species identity without reference to its environment and without reference to time (being beyond space and time is a feature of essentialism in general). With regard to environment: a genetic code is not a guideline for constructing a machine; it cannot predict phenotypic results with any accuracy. That is, "you can't read the arrangement of the body's organs in the genome. The information functions as a resource, not a step-by-step guide. To acquire meaning, it must have context: a cell's history and environment. Tracing how the phenotype emerges from interactions of genes with each other and with their environment is the key puzzle of modern genetics" (Ball, 2018, p. 550). Engineering a particular trait in a human embryo does not necessarily lead to the trait's expression (Ma et al., 2017). It can lead to the expression of a trait on the other chromosome, in this way undermining the effort to engineer a child with a particular trait. With regard to time: Genomes are highly changeable. They are also porous with their (always changing) environments. If Homo sapiens were genetically engineered to possess capacities not naturally evolved, they would still be Homo sapiens, hence not distant to us in the way that Neanderthals-who were either a different species or a subspecies of our own-are distant to us (even as $1.5 \%$ to $2.1 \%$ of the non-African human populations' genome has been inherited from Neanderthals).

The very idea of the integrity of species identity is misguided because it presupposes a permanent genome. No genome is permanent. A genetic notion of any organism can only be a notion of something that changes over time. Hence a notion of human dignity based on species identity entails somehow suspending the human germline in its current stage of evolution. (One wonders: why this stage, rather than any of its past stages or any of its possible future stages?) Like all evolved organisms, humankind was genetically different in the (distant) past; it will be genetically different in the (distant) future. It will be different naturally in addition to ways it might be different because of biotechnological interventions. Genetic essentialism, as the normative foundation for recognizing human dignity by arresting the human genome at its current stage of evolution, leads to the implausible conclusion that random, natural mutations in humans violate human dignity. (This conclusion might lead to another, equally implausible conclusion: that medical institutions should therefore be required to deploy gene editing to edit out those mutations.) Or genetic essentialism might entail that a genetic mutation does not violate human dignity because it changes the genome but because the change came about through human intent and agency. Such a conclusion demonizes human agency gratuitously.

Not all elite political instruments that invoke a notion of inherent human dignity presuppose genetic essentialism in this sense. The United Nation's 1998 Universal Declaration on the Human Genome and Human Rights frames the regulation of possible genetic engineering in terms of human dignity, asserting that "practices which are contrary to human dignity, such as reproductive cloning of human beings, shall not be permitted" (art. 11); that "no research or research applications concerning the human genome ... should prevail over respect for the ... human dignity of individuals" (art. 10); and that "practices which are contrary to human dignity, such as reproductive cloning of human beings, shall not be permitted" (art. 11). It also recognizes that the "human genome, which by its nature evolves, is subject to mutations" (art. 3) —an 


\section{Benjamin Gregg}

assertion that could justify deliberately altering the human genome, at least within some limits.

Roberto Andorno (2013, p. 89) identifies several ways in which the Declaration on the Human Genome and Human Rights pursues a notion of dignity, toward regulating human genetic engineering, without practicing essentialism. He reads the Declaration's claims that the genetic diversity within our species affirms the inherent dignity of all members (preamble), and that the human genome "underlies" the "recognition of their inherent dignity" (art. 1), as invoking the "unity of the human family and the dignity of the human person" not as genetic essentialism but rather as "expressions of philosophical ideals that transcend biology" (Andorno, 2013, p. 89). A notion of dignity that transcends biology does not claim to derive from biology in the manner of genetic essentialism. Hence, "human dignity is not the result of a particular combination of DNA, even of a very complex one" (Andorno, 2013, p. 89). Correspondingly, the Declaration states that inherent human dignity precludes "reduc [ing] individuals to their genetic characteristics" (art. 2).

In these ways, among others, the Declaration on the Human Genome and Human Rights differs from other politically prominent texts such as the United Nations' 1948 Universal Declaration of Human Rights, as well as those from politically prominent organizations such as the International Bioethics Committee and the President's Council on Bioethics. They attribute human dignity and human rights on the basis of the integrity of human species identity, defined genetically — and not, as Andorno reads the Universal Declaration on the Human Genome and Human Rights, symbolically. They invest the human genome with a moral status, treating a biological phenomenon-the genome-as if it were a human artifact. Andorno (2013) reads the Declaration symbolically as emphasizing the fact that genetic differences among members of the species are negligible from the standpoint of biological identity, that "each individual inherits the same basic genetic structure of those that preceded him or her" such that "genes are common to all past, present and future generations" (p. 89). Andorno reads the Declaration's appeal to species identity politically. He reads the claim that "everyone has a right to respect for their dignity ... regardless of their genetic characteristics" (art. 2) as a claim that all members of the species are equal in terms of worth and dignity. In that spirit, he extrapolates from the words of the text: the Declaration's "principle of equal value of all human beings does not admit any exception due to predisposition to genetic diseases" (Andorno, 2013, p. 90).
Andorno also underlines the non-essentializing quality of the Declaration with respect to its discussion of the human genome as a kind of "genetic heritage": "In a symbolic sense," the human genome is the "heritage of humanity" (art. 1). The text incorporates the genome, a biological phenomenon, into human culture in terms of a tradition self-consciously handed down within communities as a matter of cultural identity and, as such, something that might be understood by legal metaphor as a kind of collective property that devolves by a (human) right of inheritance. Future generations then appear to be the (quasi-legal) heirs of the current generation's genome.

In this respect, too, the Declaration on the Human Genome and Human Rights differs from other international instruments and organizations. For example, the 2014 European Convention on Human Rights of the Parliamentary Assembly of the Council of Europe states that the "rights to ... human dignity protected by ... the European Convention on human rights imply the right to inherit a genetic pattern which has not been artificially changed" (art. 4). The Parliamentary Assembly contrasts a "natural" genome with one artificially modified. Here, human "genetic heritage" is understood not symbolically but biologically. Yet biological heritage (unlike symbolic heritage) is a natural process without normative dimensions.

The documents and institutions that invest the human genome with an inherent moral status thereby project a social construct - moral status - onto a natural phenomenon. They practice genetic essentialism by treating the human genome as a cultural heirloom rather than as the product of natural evolution. Evolution has always included the ways in which the human species can "inscribe" itself into natural history. It does so, for example, by artificially selecting plants and animals to breed new species, to alter its own genetic makeup by consuming, for example, milk from cows and sheep and so favoring humans with a mutation that allows for adult lactose tolerance. It does so when aspects of a pregnant woman's social, material, and psychological environment influences gene expression in the fetal genome. It does so as it steadily becomes a minor coauthor of some of the Earth's geophysical systems, a phenomenon encapsulated in the theory of the Anthropocene (see Gregg, 2018). But the assertion by international instruments and organizations of a kind of species' "ownership" of its own genome-ownership in the cultural sense of declaring prohibitions on certain ways of treating it biotechnologically, toward preserving it from objectionable forms of manipulation-essentializes 


\section{Genetic engineering guided by human dignity}

culturally what is, after all, a phenomenon of natural contingency.

In a third way as well, Andorno reads the Declaration on the Human Genome and Human Rights in a manner that is non-essentialist. The Declaration notes that the human genome "by its nature evolves" and "is subject to mutations" (art. 3). From this recognition of changes to the human genome that occur in the very long term via mutation, Andorno (2013) finds it "appropriate to consider the human genome as a "common heritage of humanity' and therefore to protect it from irresponsible manipulations" (p. 89). Heritage so understood entails not the essentialist responsibility to preserve a genome construed as having inherent qualities, but the cultural responsibility of present generations toward future ones in the sense of human stewardship of life on Earth.

The Declaration differs from the 1997 Convention for the Protection of and Dignity of the Human Being with Regard to the Application of Biology and Medicine. The Convention states that the abuse of human germline genetic engineering "may endanger not only the individual but also the species itself" (art. 13). Its declares the "need to respect the human being both as an individual and as a member of the human species" and to recognize the "importance of ensuring the dignity of the human being" (preamble). According to Charo (2018), the Oviedo Convention is the "most salient instrument on human rights in the biomedical field" (p. 345). It connects the notion of a genetically based inherent dignity to a human right of individuals to be free of genetic manipulation. With regard to the "dignity of the human being," the preamble speaks of the "need to respect the human being both as an individual and as a member of the human species." The 1976 International Covenant on Economic, Social and Cultural Rights cites this sentence in its preamble and then states that "these rights derive from the inherent dignity of the human person." (Beyond those I discuss, other instruments that posit an inherent human dignity include the 1976 International Covenant of Civil and Political Rights, the 1981 Convention on the Elimination of All Forms of Discrimination Against Women, the 1987 Convention Against Torture and Other Cruel, Inhumane, Degrading Treatment or Punishment, and the 1989 Convention on the Rights of the Child.)

By means of the essentializing notion of inherent qualities-permanent and inseparable attributes, in other words, an essence-it seeks to defend human dignity by prohibiting genetic editing. (The Oviedo Convention thereby confuses changing an individual's genome with changing the germline.) De Miguel Beriain (2018) invites us to imagine a "human embryo with mutations of the Huntington gene that will inevitably lead to Huntington's disease if the embryo grows into a human being. If we edit its germline to replace the gene with a normal variant, we will modify the embryo's genome but not the human genome. The ultimate result of the intervention-a human being with a genome that does not show the specific pathological variant that triggers Huntington's disease-will not introduce any novelty into the human gene pool" (p. 3). Even Andorno (2013) is vulnerable at this point to the genetic essentialism of deriving human rights from a notion of human dignity understood as a trait inherent to human beings: "each human being, as a holder of intrinsic dignity, is entitled to inalienable rights, which are the same for all, regardless of their genetic make-up" (p. 90). To remain consistent with the rest of his reading of the Universal Declaration on the Human Genome and Human Rights, he would better view the notion of human dignity symbolically, as a social construct that, as a political tool, can be deployed in the cultural project of advocating equal legal rights for all persons.

\section{Alternative to genetic essentialism: dignity as a future person's decisional autonomy}

In place of framing human identity as the human genome (a biological identity), I frame it as human dignity: a socially constructed, political identity. I assign a political and legal status to the human genome and then derive, from that status, a human right to dignity. (I also reject the idea that human rights somehow derive from our species' genetic identity; I view them as social constructs [see Gregg, 2012, 2016, 2021].) I begin by analyzing dignity.

The international instruments I reviewed earlier wield the term "human dignity" in ways that are indeterminate in meaning. Indeterminacy hardly impedes the authors' intention: to legitimize a viewpoint. Their intention is familiar from older debates about a right to physicianassisted suicide, a right to privacy, or a right against selfincrimination, where such debates invoke a legitimizing notion of human dignity. Current debates also draw on human dignity to reject human genetic engineering (e.g., to support a future person's putative right not to be genetically modified). The term "human dignity" has no rational grounds as long as it remains indeterminate in meaning, and as long as it treats - as intuitively 


\section{Benjamin Gregg}

evident or as a first principle of a metaphysical or theological vision about human good - a putative right not to be genetically modified. To render the term rationally useful, its legitimizing function must be grounded in a determinate meaning.

Any particular definition follows from the definer's cognitive interest in defining. Mine is informed by consequentialism, a philosophical position that, while not itself scientific, does not contradict any claims of natural science or a naturalistic understanding of the human being. Consequentialism holds that whether an act is morally right depends only on it consequences, or that those actions are right that render the future world the best possible world. In a consequentialist spirit, I define "dignity" as the individual's decisional autonomy vis-à-vis other persons - such as the autonomy afforded by the right to choose whether and how to be genetically engineered. Autonomy is choice, and choice is the "recognizable capacity to assert claims," whereby a person is understood as a "potential maker of claims" (Feinberg, 1970, pp. 252-253).

One form of consequentialism is utilitarianism. Utilitarianism advocates one consequence in particular: acts whose consequences maximize the resultant good. Good is the defense of a future individual's interest in their decisional autonomy. In this context, only the present generation can defend that interest, and it can do so only if it intervenes in the embryo from which the future person will develop. Mill's (1975, pp. 10-11) corresponding principle of individual liberty champions a person's freedom of action (which presupposes the personal decisional autonomy that I define as individual dignity). But what if someone is not able to take action to avoid a future because they do not yet exist as a person? Their future decisional autonomy, and thereby dignity, can be secured because they are on a developmental continuum that begins with an embryo which, through genetic engineering, can be manipulated in ways to preclude future health consequences that would rob the individual of the capacity to exercise decisional autonomy. And while paternalism marks the act of genetically engineering the embryo from which the person will develop, their (future) overriding interest in avoiding an incapacity for decisional autonomy renders ethically acceptable the paternalism of genetically engineering the embryo. Therapeutic engineering in response to genetic disease indicated at the embryonal stage ultimately preserves their future decisional autonomy by making possible what otherwise would be enfeebled.

This understanding of dignity is hardly original. It tracks actual, if often only implicit, usage, as Macklin
(2003) pointed out two decades ago: for many participants in bioethical debates, the term means "nothing other than respect for autonomy" (p. 1419). In fact, to define dignity this way tracks various of the elite international bioethical instruments that I criticize for their genetic essentialism. The Oviedo Convention, for example, grounds dignity in a patient's right to voluntary, informed consent (one form of autonomy), just as it grounds dignity in their right to confidentiality (another form of autonomy). Article 2 states that the "interests and welfare of the human being shall prevail over the sole interest of society or science." The National Academies of Sciences, Engineering, and Medicine (2017) provide yet another example: the "principle of respect for persons requires recognition of the personal dignity of all individuals, acknowledgment of the centrality of personal choice, and respect for individual decisions" (p. 32).

Unlike these instruments, my definition of autonomy avoids essentializing, in two ways: it affirms human dignity (a) by tying it to individual autonomy rather than to the human genome and (b) by drawing on the widely accepted principle of a child's right to respect for their best interests (accepted, for example, by the 1989 Convention on the Rights of the Child, which posits the child's best interests as a guiding principle in art. 3, 9, 18, 20, and 21).

(a) Consider medical care that, as unintended side effects of disease treatment such as chemotherapy, may generate mutations of germline cells. The patient's reproductive system may be affected. Somatic editing concerns cells other than sperm and egg cells (or gametes); it affects only the patient. Germline editing concerns the nuclear DNA of gametes or embryos; it affects all of the body's cells and can be inherited by subsequent generations. Here the physician's goal is therapeutic and somatic, not enhancement and germline. Regardless of that intention, any argument that links human dignity to the human genome, such that changes to the latter compromise the former, fails to distinguish between direct and indirect types of behavior. And the argument that dignity is violated by genetic manipulation applies equally to intended genetic changes and to changes that follow inevitably from medical therapy.

Genetic essentialism also undermines the notion of human dignity as individual autonomy (a notion it otherwise supports). In the case of medical treatment, including treatment that unintentionally alters the patient's genome or the germline, withholding treatment on grounds that it would sabotage the patient's dignity 


\section{Genetic engineering guided by human dignity}

would in fact sabotage their autonomy. Refusal to provide wanted treatment would not harm the willing patient's dignity but it would affirm their autonomy inasmuch as their decisional autonomy includes the choice of potentially lifesaving medical treatment.

(b) According to Knoppers and Kleiderman (2019), "Approximately $80 \%$ of rare and often incurable and serious conditions"-including spinal muscular atrophy, beta thalassemia, and macular degeneration-"affect newborns and children, and roughly half of all rare diseases are considered to have an onset in childhood" (p. 285). Concern for the welfare of such children may in some cases recommend genetic intervention. That concern facilitates the child's best interests if it leads them to enjoy the highest possible quality of biological life. (Concern for the welfare of a child whose health would benefit significantly from genetic intervention resonates with the idea of a child's right to an open future.) Bester (2019) as well as Savulescu and Kahane (2009) contend that a political community is morally obligated to serve the child's best interest by providing available biotechnological means in selecting embryos that will become future persons. To be sure, the notion of a child's best interest is not unambiguous. As Barnes (2016) notes, a child's best interest is not independent of their contingent social environment: "it's much worse to change a person in a way that will make them subject to prejudice, stigma, and discrimination than it is to change a person in a way that will make them a part of the comfortable majority" (p. 304). But "while it's wrong to attempt to change an inter-sex child into a female child" (Barnes, 2014, p. 103), "it would be worse to turn a female child into an inter-sex child, simply because of the socially-mediated disadvantages an inter-sex person will face" (Barnes, 2016, p. 304). Or consider deaf parents who prefer a deaf child when they consider deafness not as a genetic disease so much as a culture (one they seek to preserve), and regard the child's best interest as communal membership and identity. One cannot know in advance what the child, once mature, would choose.

The autonomy-facilitating physical and cognitive welfare of the future person begins with their welfare as a child. Autonomy is anticipatory at the time of the manipulation, a kind of placeholder in utero. The future person's autonomy is held in trust by the generation that performs the manipulation (and, in particular, by the parents and the participating scientists, engineers, and physicians).

The principle of the child's best interests would limit germline editing to those forms of editing that promote welfare in a therapeutic sense. Preventing serious genetic disease is core to welfare so understood. Welfare is also served by the individual's right to science (posited by the Universal Declaration of Human Rights, art. 27: “everyone has the right to share in scientific advancement and its benefits") in the sense of access to the health benefits science can provide. (The Convention on the Rights of the Child posits the child's right "to the enjoyment of the highest attainable standard of health.”)

Note three upshots. First, recognition of human dignity does not entail a right of a future person to be free from genome modification. (This point counters the genetic essentialist claim that human dignity is respected only by respecting the "genetic heritage of humankind.") While the future person cannot consent to genetic engineering or to any of its anticipated benefits, present persons can reasonably interpret the future person's best interest as freedom from genetic disease.

Second, respect for human dignity entails engineering the genome - that of the individual but also the germline - to decrease the possibility of preventable disease in future individuals.

Third, dignity entails that the "interests and welfare" of the future individual "should have priority over the sole interest[s] of science or society" (Universal Declaration on Bioethics and Human Rights, 2005, art. 3). No just political community could condone not attempting to treat and cure a serious pathology in an embryo. And the morally acceptable interests of a person's possible descendants could never justify compromising the future person's dignity, here understood as their decisional autonomy. (This claim finds support in the Universal Declaration on Bioethics and Human Rights: the "interests and welfare of the individual should have priority over the sole interest of science or society" [art. 3]; and in the Oviedo Convention: the "interests and welfare of the human being shall prevail over the sole interest of society or science" [art. 2].) Further, invoking a future person's "priority" over possible descendants is wrongheaded. After all, reducing genetic disease would benefit those descendants; indeed, it would benefit societies worldwide. Hence dignity that entails the individual's interests and welfare can equally entail a responsibility of the current generation toward future generations. It can entail a responsibility to deploy human genetic engineering toward the treatment of genetic disease in future persons. For what is true of the future child is true of the aggregate of future children: while the beneficiary does not exist at the point of deciding whether to genetically edit, they eventually become a beneficiary as a 


\section{Benjamin Gregg}

result of having been genetically edited, whether as an embryo or as its descendant.

I distinguish my concern with genetic disease from another category of concern, genetic disability. While the categories may overlap in the case of genetically based disabilities, genetic disability - in its complexity along social dimensions - cannot be reduced to genetic disease and merits separate treatment. Consider viewpoint-differences between observers and disabled persons with respect to whether a particular disability degrades the individual's life significantly enough to recommend genetic engineering toward preventing that disability in future persons. Kahane and Savulescu (2016) argue that "disabilities such as deafness, blindness, paraplegia, and severe intellectual impairment are harmful and have a significant overall negative impact on a person's life" (p. 774). They conclude that "prospective parents have ... reason to prefer to create an able-bodied ... child rather than a disabled one" (Kahane and Savulescu, 2016, p. 775). By contrast, Barnes (2014) argues that some adults with disabilities claim that these conditions are not globally bad and that they would not choose not to have them: "having a disability makes you nonstandard or different, but it doesn't by itself make you worse off" (p. 89). There is no comparable debate with respect to genetic disease.

\section{A future person's interest in decisional autonomy}

When speaking of present persons, I speak of those persons in a position to decide whether and how to genetically modify an embryo that will develop into a future person. On a broad understanding of justice such as Mill's (2001, ch. 5), might present persons have a duty of justice toward future persons? Might future persons have rights vis-à-vis present persons? The questions pose themselves inasmuch as rights and duties that bind two or more people usually refer to two or more contemporaries who, morally and legally, stand in a more or less symmetrical relationship to one another and many of whose rights and obligations generally are roughly reciprocal (in the case of adults). By contrast, the relationship between present and future persons is neither symmetrical nor reciprocal.

First, it is asymmetrical: present persons can influence future persons but not vice versa. Exchanges occur in one direction only: toward the future. Current persons can promote the interests of future persons in certain ways just as they can harm those interests. Second, the relationship between current and future persons is nonreciprocal. For example, they cannot cooperate with each other. Third, to harm a future person's rights is to harm a particular person in the future. While present persons can have no specific knowledge of the identify of particular future persons (and no knowledge about the bodily and mental states of future persons), they can have knowledge of some of the moral dilemmas posed by possible consequences of human genetic engineering. And they can assess ways in which engineering today may violate possible rights of future persons tomorrow. Current persons need not know future persons to recognize their interests and rights.

Consider the consequences. The fact that the relationship between present and future persons is neither symmetrical nor reciprocal does not preclude the possibility of future persons as rights-bearers vis-à-vis present persons. Current persons may have duties toward the future persons who develop from genetically modified embryos. The actions of a present person can affect the interests of a future person adversely when they those actions frustrate the future person's interest in their own decisional autonomy. Frustrating that interest would violate their future right. Hence, current persons can assess at least some of the risks of genetic engineering they impose on future persons.

Second, one can have an interest even if not able to realize that interest, and one can bear rights even if one is unable to exercise them (such as children), for example, where a right "necessarily preserves one or more of the persons' interests" (Kramer, 1998, p. 62). In other words, a future person can make a valid claim to justice vis-à-vis a current person (and a current person may bear a legitimate duty of justice toward a future person) despite the fact that the future person cannot enforce that right. Hence the fact that the future person's will is not present when current humans genetically manipulate the embryo from which the future person will develop does not entail that current humans have no obligation toward future persons. After all, the difference in temporal status between a current and a future person does not necessarily entail fewer or weaker rights for future persons. Reasons against harm to a current person can apply equally to a future person.

Third, a person who develops from an embryo currently under consideration for genetic engineering bears rights as a future person. The embryo is not identical with the future person (because, among other things, a future person is also a product of environments, 


\section{Genetic engineering guided by human dignity}

experiences, and socialization in specific eras and places and cultures and under particular circumstances). An embryo cannot bear rights. But it can be a placeholder for some of the rights of the future person. Current persons respect the rights of the future person by treating the embryo in ways that respect a future person's rights, that is, by taking into account plausible interests of any future person. I focus on a future person's plausible interest in their decisional autonomy, hence their interest in having their future decisional autonomy protected or preserved in any genetic engineering decisions made by current persons. That interest does not entail that the present person is morally obligated to engineer in such a way as to increase the probability that the future person is, genetically, as "good" or "advantaged" as possible. The obligation not to harm a person's interest does not entail an obligation to maximize their interests.

Fourth, a future person's capacity as a rights bearer rests on current persons understanding themselves as members of an imagined transgenerational moral community. If members assume a standpoint based on species membership, then they need not presuppose an essential "human nature" inasmuch as species have no timeless essence: they are always evolving. Future persons enjoy rights vis-à-vis present persons on the basis of this imagined community. Current persons can imagine the standpoint of a future person in a way analogous to adults who can imagine a child's best interests: their judgment is a placeholder for the child's own judgment. And just as the adult's standpoint need not be identical with that of a child to conceive of the child's best interest, so the standpoint of the current person need not be identical with that of the future person to conceive of an interest in their decisional autonomy. Whether that conception is warranted cannot be a matter of fact; only the future person can determine as much with respect to themselves. It can only be a matter of reasoned, fallible supposition.

\section{Deliberation toward principled agreement on decisional autonomy of future persons}

The effort to define dignity as the individual's decisional autonomy vis-à-vis other persons requires the presence of an unmistakably human individual. An embryo is not such a person; it is not a person at all. While people might treat an embryo as having a moral status that disallows its treatment as an ordinary object, vulnerable to the will of its owner (hence, a staple of human embryo research governance stipulates that human embryos should not be grown in vitro in a research laboratory for longer than 14 days after the point of fertilization or at start of gastrulation, whichever occurs first), concern about how an embryo is treated reflects not the embryo but the normative preferences of the present observers. The embryo is without decisional autonomy. So the manipulation of the embryo is not wrong as such but it could be wrong with respect to a future person if present persons ascribe individual autonomy to a future person making possible a class of actions today (such as unjustified genetic engineering) that could violate the autonomy of a future person.

To protect a future person's decisional autonomy, I propose human dignity as a social construct and as a political tool. Human dignity so understood can guide principled thinking about regulating biotechnologies such as gene editing. Such thinking finds support in various international instruments, including the International Bioethics Committee (2015, paras. 117 and 118), the Council of Europe's Committee on Bioethics, as well as the Oviedo Convention, which commits signatories to "public discussion in the light ... of relevant medical, social, economic, ethical and legal implications" (art. 28) and possible applications.

I turn now to illustrating two effects of the argument from dignity conceived as social construct and political tool: (a) it facilitates public deliberation about regulating human genetic engineering and (b) public deliberation about genetic intervention operationalizes it, in political process, as an alternative to genetic essentialism.

(a) I envision input from public deliberation at three different levels of governance. At the level of international institutions, nation states that allow germline editing might work with the World Health Organization and its Expert Advisory Committee on Developing Global Standards for Governance and Oversight of Human Gene Editing. The goal is to "review the state of the science and provide advice on 'its applications, its potential usages and societal attitudes towards the different uses of this technology'; to propose potential oversight mechanisms; and to recommend global governance structures for genome editing research and potential applications" (Charo, 2019, p. 977). At the level of national institutions, such as the European Medicines Agency or the U.S. Food and Drug Administration, popular deliberation could contribute dignity-based normative perspectives for consideration by regulatory organizations pursuing the development of safe and accurate forms of genetic manipulation. And at the level of local public forums in political communities, 


\section{Benjamin Gregg}

nonexpert or lay publics could inform themselves of the relevant science and of the relevant public policy to consider how human dignity-as the decisional autonomy of future persons-might guide the legal regulation of human genetic engineering.

To be sure, the expert medical and scientific communities should always play the deciding role, perhaps with "complementary contributions from various actors who can place pressure on the research, development, and marketing of new technology ... as part of a comprehensive ecosystem of governance" (Charo, 2019, p. 978). But the voices of stakeholders in bottom-up public deliberation could inform them, not as a genetic engineering democracy of biohackers "tinkering with DNA, under the guise of 'democratizing' the life sciences" (van Beers, 2020, p. 36), but as a public informed by techniques of deliberative democracy. Such techniques include popular deliberation open to all points of view held by significant portions of the citizenry; with arguments supported by appropriate and accurate factual claims; confronted with counterarguments; and with arguments considered solely on their merits rather than with regard to, say, the prestige or political affiliation of the speaker. Members of the community would then participate in readily accessible public debates about the moral evaluation and possible legal regulation of various forms of human genetic engineering. (Elsewhere [Gregg, in press] I combine the two procedural devices of bioethics committees and deliberative democracy toward generating legitimate decisions capable of wide embrace within political community). While debates must be guided by standard norms of medical ethics, such as safety, informed consent, and the right to refuse treatment, additional norms need to be considered inasmuch as genetic engineering raises questions that cannot be dealt with solely in terms of medical ethics, such as disparities in health and in access to health care. While public deliberation will not achieve consensus (however defined, for example, as many participants as possible, or a majority of participants), it can achieve measures of shared understanding and agreement greater than otherwise possible.

(b) What kind of decisional autonomy of future persons might the current generation hold in trust? One informed by medical and scientific experts but also by popular deliberation, toward generating broad, principled agreement within political community. By principled agreement, I mean principles that inform legislation that binds clinicians in the kinds and range of choices permitted in the engineering of human embryos. I have emphasized one in particular: the notion of human dignity as an interest in the decisional autonomy of future persons. It would evaluate possible engineering choices affecting a future person who, in retrospect, could be expected to freely assent to those engineering choices taken with respect to the embryo from which they developed. Plausible expectation refers to choices capable of finding broad consent among both bioethical experts and laypersons concerning the possible preferences a future person might have regarding the relevant genetic engineering. The plausibility of broad consent relies on the plausibility of the anticipated dignity of future persons held in trust by current persons.

With regard to the capacity to exercise decisional autonomy: this notion of autonomy need not address the situation of persons unable to make decisions because they are small children or persons with severe cognitive impairment or advanced dementia. The case of an embryo cannot be analogized to the problem of determining decisional capacity for persons who possess some, but not all, of the mental capacities of "typically" functioning adult persons. Future persons are not directly vulnerable to other persons in the ways that current humans are. But they are directly vulnerable to the decisions of those who genetically modify the embryos from which they develop. That vulnerability can be addressed by regulating possible choices in the engineering of a human embryo to be compatible with dignity: choices that would not impede the future person's decisional autonomy by ensuring, or at least not interfering with, capacities needed for decisional capacity. (Any discussion of decisional capacity should note that capacity may be more like a spectrum rather than a binary: not all experiences, situations, and tasks require the same level of capacity.) Moreover, a particular individual's capacity may vary over time.) A minimal list would include a future person's capacity to communicate their choice to others; for comprehension and acquisition of knowledge of facts (whereby any plausible standard will not be so high as to exclude many people as incompetent); to appreciate relevant scientific facts, as well as relevant normative debates, relevant to genetic engineering in the ways that genetic engineering has affected their life; to appreciate the nature and significance of the decision faced by those who, in the past, determined the guidelines for human genetic engineering that governed the engineering of the embryo from which they developed; and for reasoning (whereby, again, the standard should not be so high as to classify too many persons as incompetent) (Buchanan \& Brock, 1989). 


\section{Genetic engineering guided by human dignity}

\section{Conclusion}

How might human genetic engineering best be regulated? I responded to this question by rejecting, as a regulative principle, a genetically essentialist notion of human dignity. I pursued instead a consequentialist notion of human dignity as the future person's decisional autonomy, held in trust by the current generation as it deliberates about genetically engineering the embryo from which that future person will develop. I developed this approach in six steps. First, a consequentialist notion of human dignity rejects the effort to invest the human genome with an inherent moral status. Instead, it regards all norms, including moral status, as social constructs. Second, although most biologists and philosophers of biology today do not embrace genetic essentialism, I argued that a critique of genetic essentialism is still no strawman inasmuch as genetic essentialism is widespread, especially among the lay public, and that it can be socially, politically, and institutionally pernicious. Third, I showed how the effort to identify a principle by which to regulate possible human genetic engineering -an effort typical of elite international instruments and organizations (although not of the Universal Declaration on the Human Genome and Human Rights)—is undermined by defining human dignity in genetically essentialist terms. Fourth, I offered an alternative to genetic essentialism: dignity as a future person's decisional autonomy by analogy to the widely accepted principle of a child's right to respect for its best interests. Fifth, given that the relationship between present and future persons is neither symmetrical nor reciprocal, I made a case for a future person's interest in decisional autonomy as an interest that the present generation could meet at the point of embryonal genetic manipulation. I concluded, sixth, with a sketch of popular political deliberation on regulating human genetic engineering, toward principled agreement on the decisional autonomy of future persons - all without genetic essentialism.

\section{References}

Adashi, E., \& Cohen, I. (2018). Preventing mitochondrial diseases: Embryo-sparing donor-independent options. Trends in Molecular Medicine, 24(5), 449-457.

Amato, P., Tachibana, M., Sparman, \& Mitalipov, S. (2014). Three-parent in vitro fertilization: Gene replacement for the prevention of inherited mitochondrial diseases. Fertility and Sterility, 101(1), 31-35.
Andorno, R. (2013). Principles of international biolaw: Seeking common ground at the intersection of bioethics and human rights. Éditions Bruylant.

Andreychik, M., \& Gill, M. (2015). Do natural kind beliefs about social groups contribute to prejudice? Distinguishing bio-somatic essentialism from bio-behavioral essentialism, and both of these from entitativity. Group Processes \& Intergroup Relations, 18(4), 454-474.

Atran, S., \& Henrich, J. (2010). By-products, adaptive learning heuristics, ritual displays, and group competition generate deep commitments to prosocial religions. Biological Theory, 5(1), 18-30.

Ball, P. (2018). Schrödinger's cat among biology's pigeons: 75 years of What Is Life? Nature, 560(7720), 548-550.

Barnes, E. (2014). Valuing disability, causing disability. Ethics, 125(1), 88-113.

Barnes, E. (2016). Reply to Guy Kahane and Julian Savulescu. Res Philosophica, 93(1), 295-309.

Batzir, N., Tovin, A., \& Hendel, A. (2017). Therapeutic genome editing and its potential enhancement through CRISPR guide RNA and Cas9 modifications. Pediatric Endocrinology Reviews, 14(4), 353-363.

Bayat, H., Modarressi, M., \& Rahimpour, A. (2018). The conspicuity of CRISPR-Cpf1 system as a significant breakthrough in genome editing. Current Microbiology, 75(1), 107-115.

Bester, J. (2019). The best interest standard and children: Clarifying a concept and responding to its critics. Journal of Medical Ethics, 45, 117-124.

Bratsberg, B., \& Rogeberg, O. (2018). Flynn effect and its reversal are both environmentally caused. Proceedings of the National Academy of Sciences, 115(26), 6674-6678.

Buchanan, A., \& Brock, D. (1989). Deciding for others: The ethics of surrogate decision making. Cambridge University Press.

Charo, R. A. (2018). Germline engineering and human rights. American Society of International Law Unbound, 112, 344-349.

Charo, R. A. (2019). Rogues and regulation of germline editing. New England Journal of Medicine, 380(10), 976-980.

Ching, B. H.-H., \& Xu, J. (2018). The effects of gender neuroessentialism on transprejudice: An experimental study. Sex Roles, 78, 228-241.

Convention for the Protection of and Dignity of the Human Being with Regard to the Application of Biology and Medicine (Oviedo Convention), April 4, 1997, https:/www.coe.int/en/ web/bioethics/oviedo-convention 


\section{Benjamin Gregg}

Cyranoski, D. (2019). The CRISPR-baby scandal: What's next for human gene-editing. Nature, 566(7745), 440-442.

Darwin, C. (2004). The origin of species by means of natural selection. Barnes \& Noble Classics. (Originally published 1859.)

de Miguel Beriain, I. (2018). Human dignity and gene editing: Using human dignity as an argument against modifying the human genome and germline is a logical fallacy. EMBO Reports, 19(10), 1-4.

Devitt, M. (2008). Resurrecting biological essentialism. Philosophy of Science, 75(3), 344-382.

Dupré, J. (1999). On the impossibility of a monistic account of species. In R. Wilson (Ed.), Species: New interdisciplinary essays (pp. 3-22). Cambridge University Press.

European Convention on Human Rights, March 14, 2014, http://www.assembly.coe.int/nw/xml/XRef/Xref-

XML2HTML-en.asp?fileid=20550\&lang=en

Evans, J., \& Burke, W. (2008). Genetic exceptionalism: Too much of a good thing? Genetics in Medicine, 10, 500-501.

Feinberg, J. (1970). The nature and value of human rights. Journal of Value Inquiry, 4, 243-263.

Gil-White, F. (2001). Are ethnic groups biological species to the human brain? Essentialism in our cognition of some social categories. Current Anthropology, 42(4), 515-553.

Gregg, B. (In press). Political bioethics. Journal of Medicine and Philosophy.

Gregg, B. (2012). Human rights as social construction. Cambridge University Press.

Gregg, B. (2016). The human rights state: Justice within and beyond sovereign nations. University of Pennsylvania Press.

Gregg, B. (2018). Human genetic engineering: Biotic justice in the anthropocene? In D. DellaSala \& M. Goldstein (Eds.), Encyclopedia of the anthropocene (Vol. 4, pp. 351-359). Elsevier.

Gregg, B. (2021). Against essentialism in conceptions of human rights and human nature. Human Rights Quarterly, 43(2), 313-328.

Griffiths, P. (2002). What is innateness? Monist, 85(1), 70-85.

Haslam, N. \& Levy, S. (2006). Essentialist beliefs about homosexuality: Structure and implications for prejudice. Society for Personality and Social Psychology Bulletin, 32(4), 471-485.

Heine, S. (2017). DNA is not destiny: The remarkable, completely misunderstood relationship between you and your genes. W. W. Norton.
Heine, S., Cheung, B., \& Schmalor, A. (2019). Making sense of genetics: The problem of essentialism. Hastings Center Report, 49(3), S19-S26.

Ho, P., \& Chen, Y. (2017). Mammalian synthetic biology in the age of genome editing and personalized medicine. Current Opinions in Chemical Biology, 40, 57-64.

Huang, J., Wang, Y., \& Zhao, J. (2017). CRISPR editing in biological and biomedical investigation. Journal of Cell Physiology, 233(5), 3875-3891.

Hull, D. (1992). A matter of individuality. In M. Ereshefsky (Ed.), The units of evolution: Essays on the nature of species (pp. 293-316). MIT Press.

International Bioethics Committee. (2015, October 2). Report of the IBC on updating its reflection on the human genome and human rights. https://unesdoc.unesco.org/ark:/48223/ pf0000233258

International Covenant on Economic, Social and Cultural Rights, January 3, 1976, https:/www.ohchr.org/en/ professionalinterest/pages/cescr.aspx

Ishii, T. (2017). The ethics of creating genetically modified children using genome editing. Current Opinion in Endocrinology, Diabetes and Obesity, 24(6), 418-423.

Jackson, J., \& Depew, D. (2017). Darwinism, democracy, and race: American anthropology and evolutionary biology in the twentieth century. Routledge.

Jasanoff, S., Hurlbut, J., \& Saha, K. (2015). CRISPR democracy: Gene editing and the need for inclusive deliberation. Issues in Science and Technology, 32(1), 25-32.

Kahane, G., \& Savulescu, J. (2016). Disability and mere difference. Ethics, 126(3), 774-788.

Kang, X., He, W., Huang, Y., Yu, Q., Chen, Y., Gao, X., Sun, X., \& Fan, Y. (2016). Introducing precise genetic modifications into human 3PN embryos by CRISPR/Cas-mediated genome editing. Journal of Assisted Reproduction and Genetics, 33(5), 581-588.

Knoppers, B., \& Kleiderman, E. (2019). Heritable genome editing: Who speaks for "future" children? The CRISPR Journal, 2(5), 285-292.

Kramer, M. (1998). Rights without trimmings. In M. Kramer, N. Simmonds, \& H. Steiner (Eds.), A debate over rights (pp. 7-111). Clarendon Press.

Lewontin, R. (1972). The apportionment of human diversity. Evolutionary Biology, 6, 381-398.

Li, Y., Song, Y., Liu, B., \& Yu, X. (2016). The potential application and challenge of powerful CRISPR/Cas9 system in cardiovascular research. International Journal of Cardiology, 227, 191-193. 


\section{Genetic engineering guided by human dignity}

Ma, H., Marti-Gutierrez, N., Park, S. W., Wu, J., Lee, Y., Suzuki, K., ... \& Mitalipov, S. (2017). Correction of a pathogenic gene mutation in human embryos. Nature, 548 (7668), 413-419.

Macklin, R. (2003). Dignity is a useless concept. British Medical Journal, 327(7429), 1419-1420.

Matthen, M. (1998). Biological universals and the nature of fear. Journal of Philosophy, 95(3), 105-132.

Mianné, J., Codner, G., Caulder, A., Fell, R., Hutchison, M., King, R., Stewart, M., Wells, S., \& Teboul, L. (2017). Analysing the outcome of CRISPR-aided genome editing in embryos: Screening, genotyping and quality control. Methods, 121-122, 68-76.

Mill, J. S. (1975). On liberty. W.W. Norton. (Originally published 1858.)

Mill, J.S. (2001). Utilitarianism. Batoche Books. (Originally published 1863.)

Miyamoto, T., Akutsu, S., \& Matsuura, S. (2018). Updated summary of genome editing technology in human cultured cells linked to human genetics studies. Journal of Human Genetics, 63(2), 133-143.

Morton, T., Hornsey, M., \& Postmes, G. (2009). Shifting ground: The variable use of essentialism in contexts of inclusion and exclusion. British Journal of Social Psychology, 48(Pt. 1), 35-59.

National Academies of Sciences, Engineering, and Medicine. (2017). Human genome editing: science, ethics, and governance. National Academies Press.

Nuffield Council on Bioethics. (2018). Genome editing and human reproduction: Social and ethical issues. Nuffield Council on Bioethics.

Okasha, S. (2002). Darwinian metaphysics: Species and the question of essentialism. Synthese, 131(2), 191-213.
President's Council on Bioethics. (2002, July). Human cloning and human dignity: An ethical inquiry. https://

bioethicsarchive.georgetown.edu/pcbe/reports/cloningreport/

Rosenberg, A. (1985). The structure of biological science. Cambridge University Press.

Rosenberg, N. (2011). A population-genetic perspective on the similarities and differences among worldwide human populations. Human Biology, 83(6), 659-684.

Savulescu, J., \& Kahane, G. 2009. The moral obligation to create children with the best chance of the best life. Bioethics, 23(5), 274-290.

Sober, E. (1992). Evolution, population thinking and essentialism. In M. Ereshefsky (Ed.), The units of evolution: Essays on the nature of species (pp. 247-278). MIT Press.

Sober, E. (1993). Philosophy of Biology. Boulder: Westview.

Sterelny, K., \& Griffiths, P. (1999). Sex and death. University of Chicago Press.

Tang, H., \& Schrager, J. (2016). CRISPR/Cas-mediated genome editing to treat EGFR-mutant lung cancer: A personalized molecular surgical therapy. EMBO Molecular Medicine, 8(2), 83-85.

Universal Declaration on Bioethics and Human Rights, October 19, 2005, https://en.unesco.org/themes/ethics-scienceand-technology/bioethics-and-human-rights

Universal Declaration on the Human Genome and Human Rights, endorsed December 9, 1998, https://www.ohchr.org/en/ professionalinterest/pages/humangenomeandhumanrights.aspx

Universal Declaration of Human Rights, December 10, 1948, https://www.un.org/sites/un2.un.org/files/udhr.pdf

van Beers, B. (2020). Rewriting the human genome, rewriting human rights law? Human rights, human dignity, and human germline modification in the CRISPR era. Journal of Law and the Biosciences, 7(1), lsaa006. 